\title{
DIGITAL COMMONS
}

\section{Crítica de la técnica y humanismo comprometido en Ernesto Sábato}

\author{
Damián Pachón Soto
}

Follow this and additional works at: https://digitalcommons.usf.edu/surcosur

Part of the Bilingual, Multilingual, and Multicultural Education Commons, Creative Writing Commons, Critical and Cultural Studies Commons, and the Latin American Languages and Societies Commons

\section{Recommended Citation}

Pachón Soto, Damián. 2011. Crítica de la técnica y humanismo comprometido en Ernesto Sábato. Revista Surco Sur, Vol. 2: Iss. 4, 52-55.

DOI: http://dx.doi.org/10.5038/2157-5231.2.4.16

Available at: https://digitalcommons.usf.edu/surcosur/vol2/iss4/16

This HONRAR, HONRA is brought to you for free and open access by the Open Access Journals at Digital Commons @ University of South Florida. It has been accepted for inclusion in Revista Surco Sur by an authorized editor of Digital Commons @ University of South Florida. For more information, please contact digitalcommons@usf.edu. 


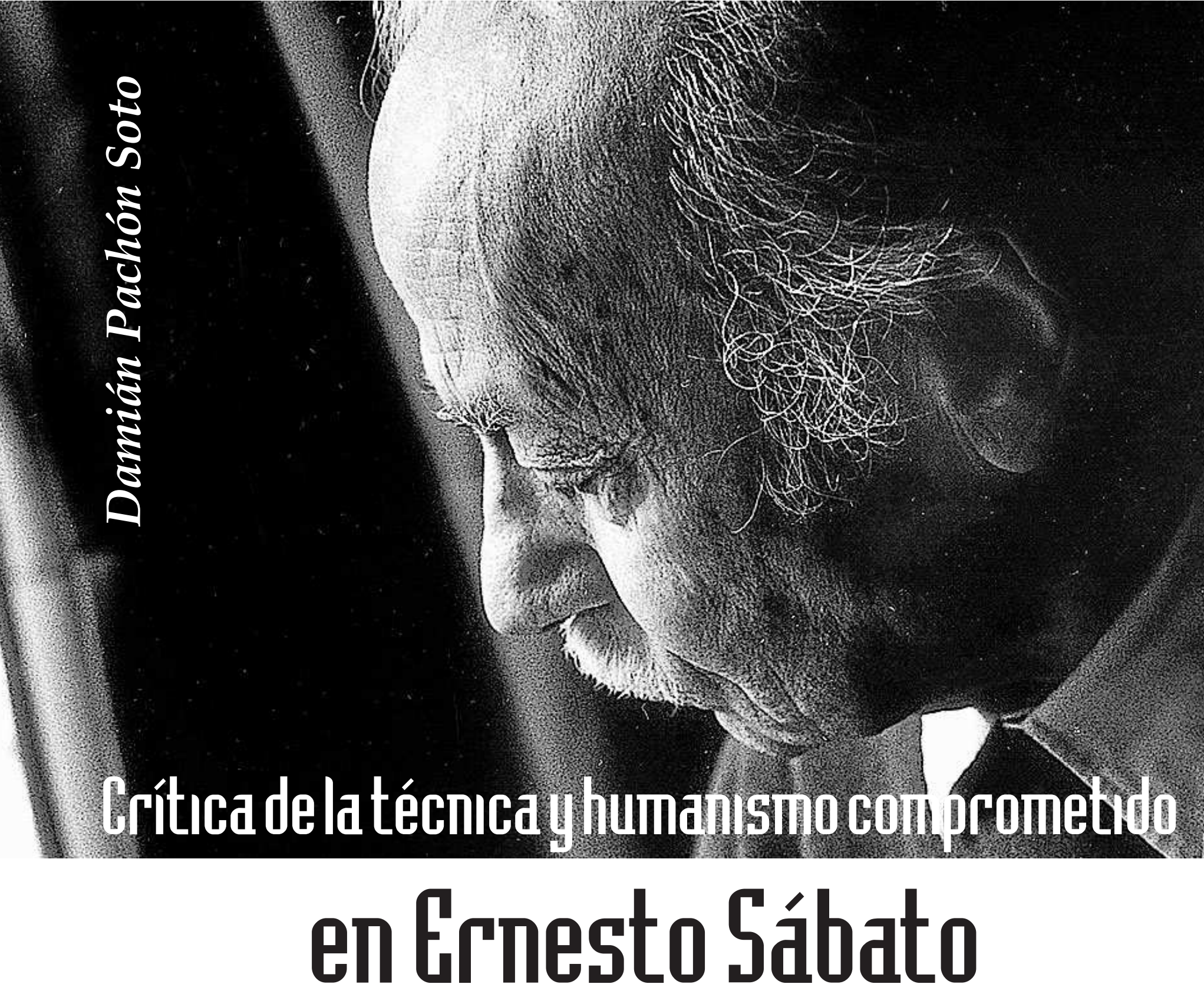

De la fábrica en que ejecuta un movimiento tipo, o desde un anónimo puesto de burócrata en que maneja expedientes, o desde el fondo de un laboratorio en que como modesto empleado kafkiano pasa la vida midiendo placas espectográficas y apilando millares de números indiferentes, el hombre-cosa es incorporado con un número a un escuadrón, una compañía, un regimiento, una división y un ejército también numerados. Y en el que un Estado Mayor, tan invisible como el tribunal del proceso kafkiano, mueve las piezas de un monstruoso ajedrez, mediante la ayuda de mapas matemáticos, telémetros y relieves aerofotogramétricos. Guiado por teléfonos y radios, el hombre-cosa avanza hacia posiciones marcadas con letras y números. Y cuando muere por obra de una bala anónima es enterrado en un cementerio geométrico. Uno de entre todos es llevado a una tumba simbólica que recibe el significativo nombre de Tumba del Soldado Desconocido. Que es como decir: Tumba del Hombre-Cosa.

ERnESTO SÁBATO, Hombres y engranajes.
En su libro La resistencia (2000) había escrito Ernesto Sábato: "Como la luz de la aurora que se presiente en la oscuridad de la noche, así de cerca está la muerte de mí. Es una presencia invisible". Estas palabras, que recuerdan las metáforas de María Zambrano, una de las lecturas preferidas de Sábato, expresan esa relación que el escritor tuvo con la muerte. Sábato pasó del natural temor que siente todo ser humano ante la muerte a la tranquilidad, al saber que se ha vivido bien, sinceramente, defendiendo las convicciones; al saber que ya no le debemos nada a la vida porque estamos plenos y realizados, y que por eso mismo se puede ir sin temor a los brazos de ese vientre oscuro de donde algún día emergimos.

Sábato fue un escritor existencial. Su obra tiene una marca indeleble de la "época de las catástrofes", tal como Eric Hobsbawn llamó a ese período del siglo pasado a partir de 1914. 
$\mathrm{Su}$ inicial militancia en el comunismo en los años 30, su viaje a Europa a representar al partido comunista de Argentina, sus estudios del marxismo y su posterior ingreso al mundo de la ciencia, adonde llegó a trabajar en el Laboratorio Curie en París (1938) y luego en el MIT en Massachusetts, fueron sustituidos por la literatura a comienzos de los años 40. Fue un divorcio definitivo, producido por la convicción de que la ciencia podía llevar a la humanidad al desastre, tal como había advertido Bertrand Russell en su librito Ícaro o el futuro de la ciencia, de 1924, autor de quien Sábato tradujo El $A B C$ de la relatividad para lengua española. En efecto, en su primer libro, Uno y el universo, de 1945, el desencanto de Sábato con la ciencia era manifiesto: "La ciencia ha sido un compañero de viaje, durante un trecho, pero ya ha quedado atrás". Sábato estuvo convencido de dos cosas.

En primer lugar, de que la ciencia no tenía que ver con los aspectos fundamentales del hombre, su vida, sus emociones, la felicidad, el sentido de la vida. Así lo expresará en su libro Hombres y engranajes, de 1951: "La ciencia estricta - la ciencia matematizable- es ajena a todo lo que es más valioso para el ser humano: sus emociones, sus sentimientos, sus vivencias de arte o de justicia, sus angustias metafísicas". En segundo lugar, para Sábato, la ciencia reducía el hombre a número, a dato, a "hombre-cosa". La ciencia despojaba y empobrecía las entrañas humanas. En Heterodoxias va a decirnos: "El racionalismo, adorador de lo abstracto [...] pretendió separar la razón de la emoción y la voluntad, y mediante ella y sólo mediante ella conocer el mundo. Como la razón es universal, pues dos más dos valen cuatro para todos, y como lo válido para todo el mundo parece ser la Verdad, entonces lo individual era lo falso. Así se desacreditó lo subjetivo, lo emocional, lo sentimental. Así fue guillotinado el hombre concreto [...] en nombre de la Objetividad y la Verdad". Y en Sobre héroes y tumbas, de 1961, novela de la trilogía que sigue a El túnel (1948), nos dice: "Creo que la Verdad está bien en las matemáticas, la química, la filosofía. No en la vida. En la vida es más importante la ilusión, la imaginación, el deseo, la esperanza". Todo esto lo llevó, igualmente, a la convicción como ya lo había hecho Baudelaire- de que no se puede confundir el progreso material con el progreso ético y moral de la humanidad: "Es fácil, en efecto, probar la superioridad del avión sobre la carreta, pero ¿cómo probar el progreso moral o político?", nos dice en 1951.

Como hijo de la Segunda Guerra Mundial, como contemporáneo del fascismo soviético y de la dictadura de Franco en España, esto es, como testigo de lo que Theodor Adorno llamó "la vida dañada", Sábato se hizo a una visión sombría y trágica del mundo, crítico de la civilización técnico-científica, de las democracias totalitarias, de la miseria y el embobecimiento que el capitalismo traía día a día con su cúmulo de cachivaches y abalorios. Este sentimiento de desesperanza, de desolación, tristeza, pesimismo, es palpable en sus libros, tanto en las novelas como en sus ensayos "filosófico-científicos". Es este pensamiento aquello que lo acercó al existencialismo. Valga recordar de paso que su primera novela, El túnel, de 1948, fue traducida al francés gracias a los oficios de Albert Camus. La primera página de esa novela revela a un Sábato corrosivamente pesimista: "En realidad siempre he pensado que no hay memoria colectiva, lo que quizá sea una forma de defensa de la especie humana. La frase 'todo tiempo pasado fue mejor' no indica que antes sucedieran menos cosas malas sino que felizmente - la gente las echa en el olvido. Desde luego, semejante frase no tiene validez universal; yo, por ejemplo, me caracterizo por recordar preferentemente los hechos malos y, así, casi pudiera decir que 'todo tiempo pasado fue peor', si no fuera porque el presente me parece tan horrible como el pasado; recuerdo tantas calamidades, tantos rostros cínicos y crueles, tanta malas acciones, que la memoria es para mí como la temerosa luz que alumbra un sórdido museo de la vergüenza. [...] Que el mundo es horrible es una verdad que no necesita demostración".

Sábato fue un escritor insular, para repetir lo que Darío Botero dijo de José Saramago, pues sus novelas son integrales, mezclan la
[...] Fue un divorcio definitivo, producido por la convicción de que la ciencia podía llevar a la humanidad al desastre, [...] 
Para Sábato se trataba no de darle vuelta atrás a la rueda de la historia sino de enmendar $y$ recomponer lo que en ella se ha salido de madre, sus efectos nocivos.

autobiografía con las reflexiones filosóficas, profundos análisis psicológicos y también la inclusión novelada de la historia de Argentina. Sus novelas presentan varios planos, en lo cual consistía su "novela total". Esto caracteriza a Sobres héroes y tumbas (1961) —novela que contiene esa magistral y delirante pieza que es el Informe sobre ciegos-, así como el último título de la trilogía novelística: Abaddon el exterminador (1974). Igualmente, ese humanismo, la crítica de la adulación de la técnica (tecnolatría), crítica del capitalismo, su reivindicación de la utopía, sus discusiones sobre la literatura continental y universal, están presentes en su libro autobiográfico Antes del fin (1998) y en otros, como La resistencia, ya referida, y Diálogos con Jorge Luis Borges (1976). A esto debemos agregarle su personal visión sobre la novela y la literatura expuesta en $E l$ escritor y sus fantasmas (1963). Es toda esta labor como escritor lo que le fue reconocido en 1984 con el Premio Cervantes de Literatura, equivalente al Nobel en lengua castellana.

Una faceta importante de Sábato, que no se puede pasar por alto, fue su activismo a favor de los derechos humanos y su denuncia de los horrores cometidos por la dictadura en Argentina entre 1976 y 1983. Fue así como se comprometió en su labor pública más humanitaria y más reconocida, en la Comisión Nacional Sobre la Desaparición de Personas (Conadep). De esa participación salió el conocido informe "Nunca más" en 1984, que pasó a ser el símbolo del ingreso de la democracia en el país austral, después de una de las dictaduras más atroces del Cono Sur. Habrá que recordar con el fallecido escritor argentino que "no hay dictaduras malas ni dictaduras buenas; todas son igualmente abominables".
Por último, a pesar del pesimismo visceral sobre el futuro de la civilización, de la certeza de que "asistimos a un desierto superpoblado", Sábato siempre conservó la esperanza, una vena de utopía. ¿Cuál fue su humanismo? ¿Cuáles fueron esos valores que reivindicó para humanizar al hombre? Frente a las prédicas actuales de un poshumanismo de Peter Sloterdijk, con Sábato se da una apuesta por la reivindicación de cierto tipo de humanidad. Porque podemos decir que, mientras el mundo no esté bien, esto es, mientras existan el hambre, la violencia, la injusticia, la muerte prematura de vidas no realizadas e incompletas; mientras haya niños con hambre, mujeres maltratadas, personas sin salud, ancianos a la deriva de sus últimas soledades; mientras el hombre siga con la fiesta de la autoantropofagia, mientras permanezcamos bajo el "totalitarismo mediático global" y "bajo la dictadura de la economía", es válido conservar una vena de utopía y humanismo. Para Sábato se trataba no de darle vuelta atrás a la rueda de la historia sino de enmendar y recomponer lo que en ella se ha salido de madre, sus efectos nocivos. De tal manera que no se trata de deshacer la ciencia, la técnica, sino de resistir frente a este mundo y postular la recuperación de algunos valores necesarios para la convivencia, la justicia y la libertad real del hombre.

Interesa señalar aquí que, para Sábato, en la actual sociedad se han perdido la solidaridad, el afecto, la vergüenza; se ha renunciado, en medio de lo que podemos llamar el fervor del "enclaustramiento por lo técnico" de la "forma-vida-frenesí", a experiencias profundas como el amor y la amistad; nos hemos despojado de la entraña, nos hemos vaciado más y vagamos con la "conciencia arrobada" y con la atención fragmentada por los destellos del espectáculo, del brillo de los desfiles de moda, la suntuosidad de las estrellas del entertainment y la sociedad hipermasificada, la
Su pensamiento es la apuesta por la sonrisa, la alegría, las caricias, la responsabilidad por el otro al estilo Levinas, la belleza, la bondad,[...] 
mercancía y los millones de bites de información que nuestros endebles cerebros no alcanzan a procesar. Es por todo lo anterior, por la soledad posmoderna, el aislamiento, el empobrecimiento de los vínculos humanos, etcétera, que Sábato propone la "salvación por los afectos"; el encuentro, el diálogo en los cafés, el intercambio y el reconocimiento con el otro, o lo que hoy llamamos interculturalidad. Su pensamiento es la apuesta por la sonrisa, la alegría, las caricias, la responsabilidad por el otro al estilo Levinas, la belleza, la bondad, pues "únicamente los valores del espíritu pueden salvarnos". En este mismo sentido dice: "Un lujo verdadero es un encuentro humano, un momento de silencio ante la creación, el gozo de una obra de arte o de un trabajo bien hecho". Eso debemos recuperarlo. Debemos hacer algo, pues "no podemos quedar fijados en el pasado y tampoco deleitarnos en la mirada del abismo". Y esa lucha contra la inacción es necesaria, pues "sobre nuestras generaciones pesa el destino, es ésta nuestra responsabilidad histórica". De ahí que "sólo quienes sean capaces de encarnar la utopía serán aptos para el combate decisivo, el de recuperar cuanto de humano se haya perdido".
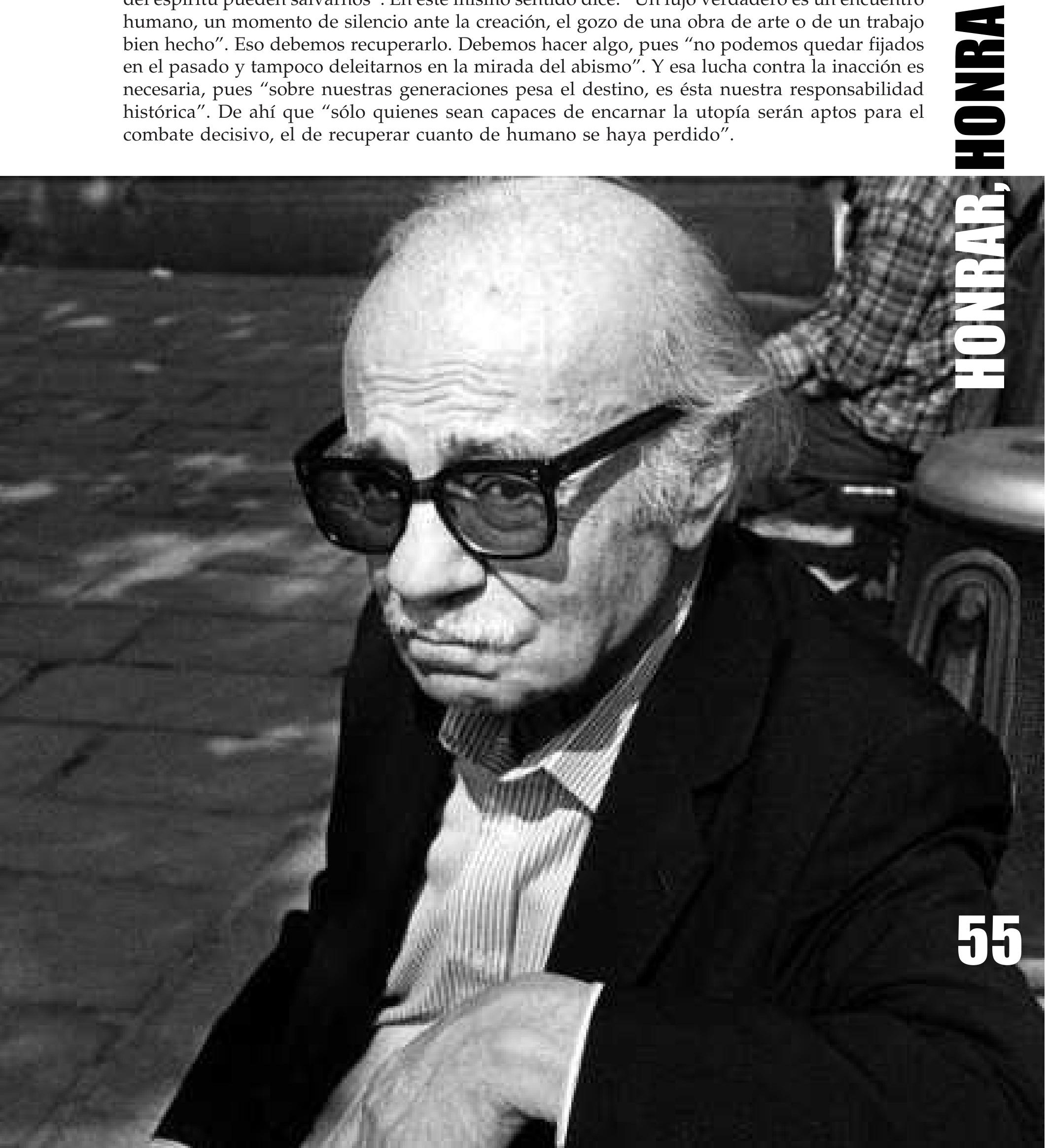